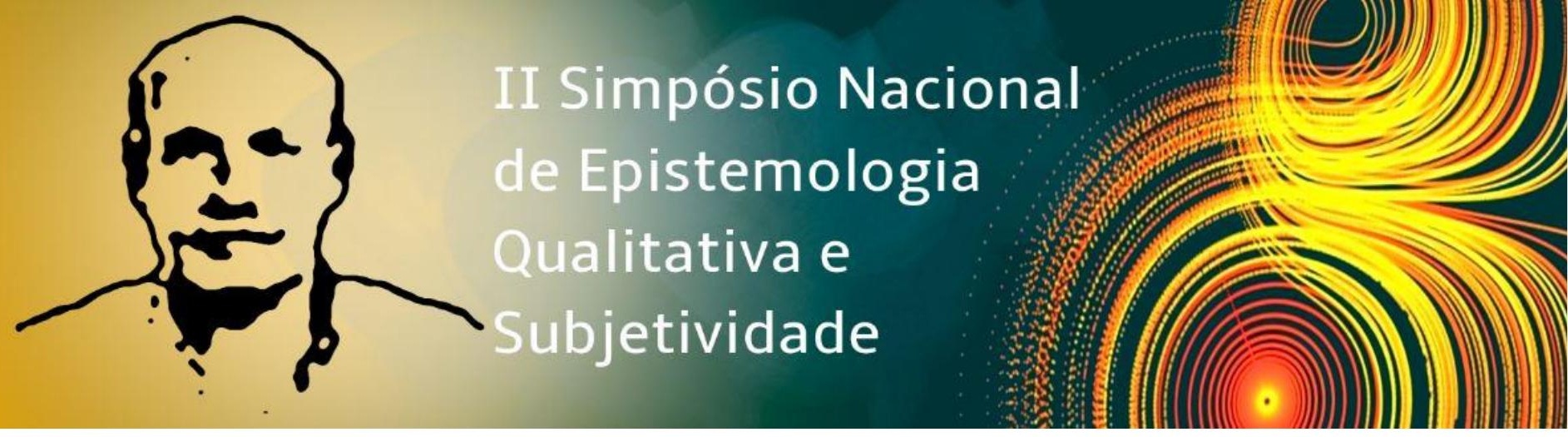

Eixo temático: A dimensão subjetiva da deficiência no processo de inclusão escolar

\title{
A CONSTITUIÇÃO SUBJETIVA DE ESTUDANTES COM DEFICIÊNCIA INTELECTUAL E APRENDIZAGEM ESCOLAR
}

Marlene Chaves, UnB, marlene494@gmail.com Prof $^{a}$ Dr $^{a}$ Maristela Rossato, UnB, maristelarossato@gmail.com

\section{RESUMO}

O objetivo desse estudo foi analisar a constituição subjetiva de estudantes com deficiência intelectual no contexto inclusivo, demarcando um posicionamento de reconhecimento das possibilidades de constituição e expressão do estudante como sujeito do seu processo de aprendizagem e desenvolvimento. Teoricamente a discussão está fundamentada na perspectiva cultural-histórica do desenvolvimento humano a partir dos estudos de Vigotski, e suas contribuições sobre a deficiência, além da Teoria da Subjetividade desenvolvida por González Rey e colaboradores. A pesquisa desenvolvida foi de natureza qualitativa, por meio da metodologia construtivo-interpretativa, pautada nas relações dialógicas entre o pesquisador e os participantes, enfatizando a importância da singularidade dos processos de investigação e concebendo a produção do conhecimento no processo construtivo-interpretativo. Realizou-se a pesquisa com duas participantes com deficiência intelectual do terceiro ano do Ensino Fundamental em classe inclusiva de uma escola pública do Distrito Federal. A produção das informações ocorreu por meio de instrumentos favorecedores da expressão das participantes: dinâmicas conversacionais, entrevista, desenho, conte-me sobre você, linha da vida escolar, complemento de frases lúdico e observação participante ativa. Por meio da análise das informações produzidas com as participantes, considera-se haver a negação da condição de 


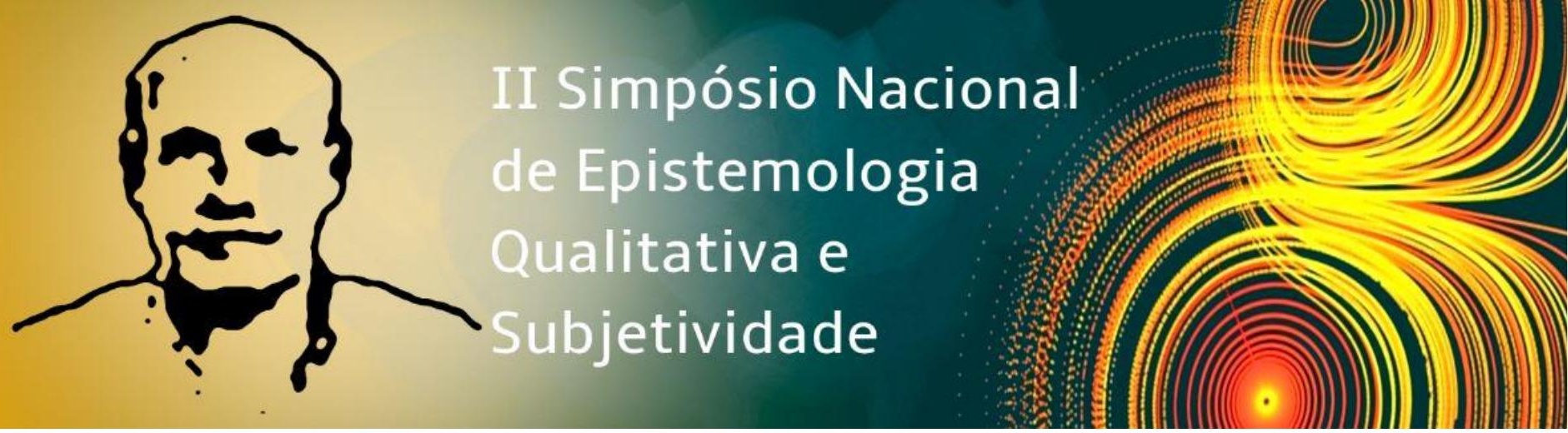

sujeito da aprendizagem escolar, uma vez que para a consolidação do processo de aprendizado, se faz premente a mobilização de novos recursos subjetivos, assim como de novas ações e relações de ensino capazes de promover o desenvolvimento e a aprendizagem do estudante com deficiência intelectual. Desta forma, busca-se refletir e compreender por meio da Teoria da subjetividade, como a constituição da subjetividade do estudante com deficiência intelectual pode mobilizar os processos da aprendizagem escolar.

Palavras-chave: subjetividade, deficiência intelectual, aprendizagem escolar.

\section{REFERÊNCIAS:}

ANACHE, A. A.; NUERNEBERG, A. H. Sociedade contemporânea, subjetividade e educação especial na perspectiva inclusiva. In A. A. Anache, B. J. L. Scoz \& M. I. S. Castanho (Eds.) Sociedade contemporânea: Subjetividade e educação (pp. 54-74). São Paulo, SP: Memmon, 2015 .

ANACHE. A. A. Aprendizagem de pessoas com deficiência intelectual: Desafios para o professor. In A. Mitjáns Martinez \& M. C. V. R. Tacca (Eds.), Possibilidades de aprendizagem: Ações pedagógicas para alunos com dificuldade e deficiência (pp. 109-138). Campinas, SP: Alínea, 2011.

GONZÁLEZ REY, F. Pesquisa qualitativa e subjetividade: Os processos de construção da informação. São Paulo, SP: Pioneira Thomson Learning, 2005.

GONZÁLEZ REY, F. L. O sujeito que aprende: Desafios do desenvolvimento do tema da aprendizagem na psicologia e na prática pedagógica. In M. C. Tacca. (Ed.). Aprendizagem e Trabalho Pedagógico. 3. ed. Campinas, SP: Alínea, 2014.

GONZÁLEZ REY, F. L., e MITJÁNS MARTINEZ, A. Subjetividade: teoria, epistemologia e método. Campinas-SP: Alínea, 2017.

MITJÁNS MARTINEZ, A., e GONZÁLEZ REY, F. Psicologia, educação e aprendizagem escolar: avançando na contribuição da leitura cultural histórica. São Paulo, SP: Cortez, 2017. 


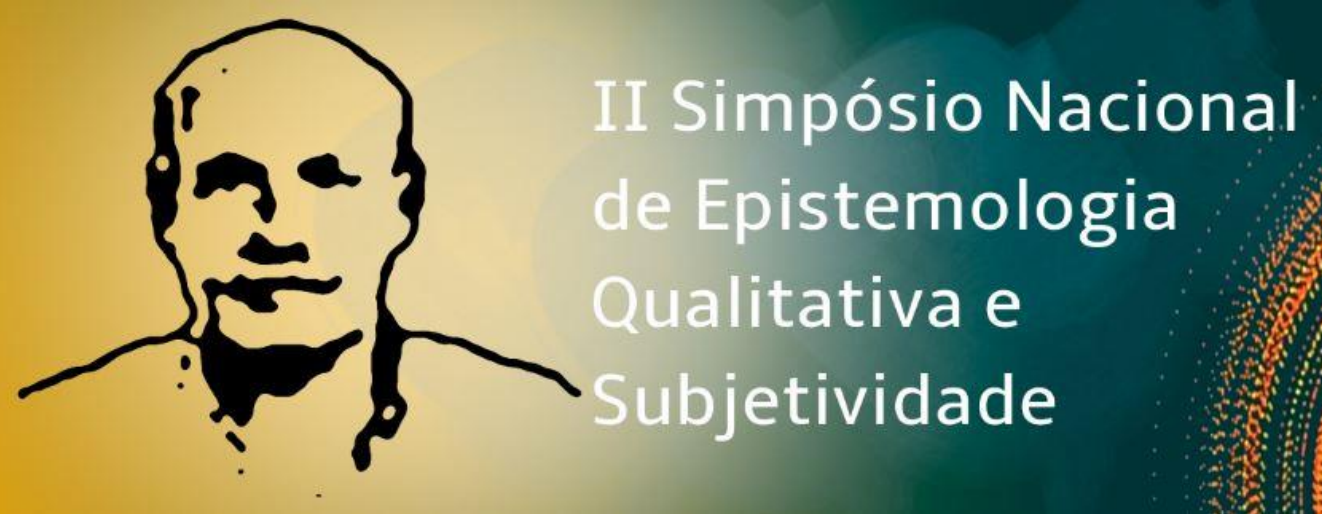

ROSSATO, M. O movimento da subjetividade no processo de superação das dificuldades de aprendizagem escolar. (Tese de doutorado). Universidade de Brasília, Brasília-DF, 2009.

VYGOTSKI, L. S. Obras Escogidas-V Fundamentos de defectologia. Madrid, Espanha: Machado Grupo de Distribuición, 1997. 